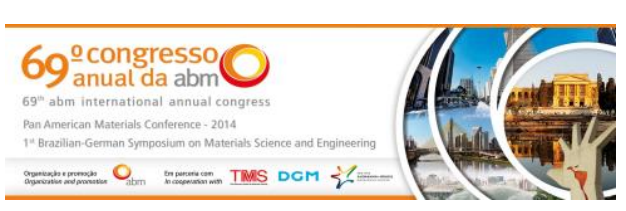

Tema: Engenharia de superfície

\title{
CARACTERIZAÇÃO DE CAMADAS PRODUZIDAS POR ASPERSÃO TÉRMICA*
}

\author{
Josiane Fernandes de Souza ${ }^{1}$ \\ Marcos Dorigão Manfrinato ${ }^{2}$ \\ Octavio Carvalho 3 \\ Flavio Camargo 4 \\ Jeferson Aparecido Moreto ${ }^{5}$ \\ Luciana Sgarbi Rossino ${ }^{6}$
}

\begin{abstract}
Resumo
O desenvolvimento deste trabalho refere-se ao estudo da resistência à adesão de camadas aspergidas termicamente e a quantificação, análise e a influência da presença de poros na microdureza, rugosidade e resistência ao desgaste das camadas produzidas. O método de aplicação das camadas produzidas por aspersão térmica foi o HVOF (High Velocity Oxi-Fuel) em substrato de aço SAE 1020. Observouse que a composição química da camada produzida por aspersão térmica influenciou significativamente na dureza e resistência ao desgaste dos materiais estudados. Percebeu-se que a rugosidade variou de acordo com a preparação superficial do substrato e que a resistência à adesão foi maior para os materiais que possuem maior dureza. A porosidade não influenciou a resistência à adesão das camadas aspergidas.
\end{abstract} Palavras-chave: Aspersão térmica; HVOF; Porosidade; Adesão.

\section{Abstract}

\section{THERMAL SPRAY COATING CHARACTERIZATION}

The development of this work refers to the study of adhesion strength for thermally sprayed layers and quantification, analysis and the influence of the presence of pores on microhardness, roughness and wear resistance of the layers produced. The method of application of the layers produced by the HVOF thermal spray was (High Velocity Oxy-Fuel) in SAE 1020 steel substrate. It was observed that the chemical composition of the layer produced by thermal spraying influence significantly the hardness and wear resistance of the materials studied. It was noticed that the roughness varied with the surface preparation of the substrate and the adhesion strength was greater for materials having higher hardness. The porosity did not influence the adhesion strength of the sprayed layers.

Keywords: Thermal spraying; HVOF; Porosity; Adhesion.

1 Graduação em Processos Metalúrgicos, FATEC-Sorocaba, Sorocaba, SP, Brasil.

2 Graduação em Física, Mestre em Ciência e Engenharia de Materiais, Professor Assistente, FATECSorocaba, Sorocaba, SP, Brasil.

3 Graduação em Engenharia de Produção, Engenharia, OGRAMAC Engenharia de Superfície, Santo Antônio da Posse, SP, Brasil.

4 Diretor Comercial/OGRAMAC Engenharia de Superfície, Santo Antônio da Posse, SP, Brasil.

5 Graduação em Física, Doutor em Ciência e Engenharia de Materiais, Professor Adjunto, IF Goiano, Morrinhos, GO, Brasil.

6 Graduação em Engenharia Química, Doutorado em Ciência e Engenharia de Materiais, Professora Assistente, FATEC-Sorocaba, Sorocaba, SP, Brasil.

\footnotetext{
* Contribuição técnica ao $69^{\circ}$ Congresso Anual da ABM - Internacional e ao 14ํㅡㄹ ENEMET - Encontro Nacional de Estudantes de Engenharia Metalúrgica, de Materiais e de Minas, 21 a 25 de julho de 2014, São Paulo, SP, Brasil.
} 


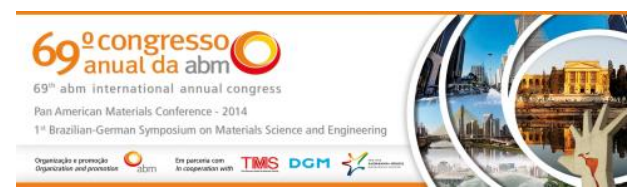

\section{INTRODUÇÃO}

A utilização de revestimentos protetores aplicados através do processo de aspersão térmica tem como objetivo a proteção de peças e componentes contra desgaste abrasivo, adesivo, erosivo, fadiga superficial e corrosão. Também é utilizada em peças que necessite de isolamento térmico e isolamento elétrico [1].

Todos os materiais que passam pelo processo de aspersão térmica apresentam uma porcentagem de poros, podendo ela ser alta, média ou baixa, as quais se concentram entre as partículas que se achatam e aderem-se ás irregularidades da superfície. A porosidade ocorre devido à incompleta cobertura da superfície pelas partículas subsequentes que são aspergidas [1].

A formação desses poros está relacionada com alguns parâmetros de aplicação. Baixas temperaturas e/ou baixas velocidades de impacto, assim como partículas grandes, tendem a aumentar a porosidade. Maiores distâncias de aplicação de partículas aspergidas termicamente, assim como uma menor granulometria do pó, resultam em maiores valores de porosidades obtidas nos revestimentos [2].

A influência na propriedade das camadas aspergidas está diretamente associada aos processos de combate à corrosão, medidas de rugosidade, resistência à adesão e microdureza. A determinação de área de porosidade percentual é importante a fim de monitorar o efeito das variáveis de parâmetros de pulverização e a adequação de um revestimento para a sua finalidade pretendida. Dependendo da aplicação, alguma ou nenhuma porosidade pode ser tolerável [3].

Em alguns casos essa porosidade pode ser benéfica dependendo de sua aplicação. No caso de aplicação em indústria a porosidade deve ser controlada, pois assim não prejudicam a resistência ao desgaste e a corrosão, já em implantes biomédicos essa porosidade pode ser benéfica, pois quando um material poroso é introduzido ao corpo humano pode haver uma maior aceitação do organismo. A porosidade acelera e uniformiza a fixação biológica, pois facilita o crescimento ósseo e a formação de fortes pontes que garantem a osteointegração e a esperada fixação secundaria dos implantes [4].

O objetivo deste trabalho é analisar a porcentagem de porosidade nas camadas aspergidas através de analises metalográficas e analises química, além de determinar a taxa de desgaste, e a influência desses poros na microdureza e rugosidade dos revestimentos.

\section{MATERIAIS E MÉTODOS}

O substrato utilizado para o desenvolvimento deste trabalho foi o aço SAE 1020. Os corpos de prova, os quais foram usinados na FATEC - Sorocaba. Após usinados foram enviados para a empresa Ogramac - Engenharia de Superfície, localizada em Santo Antônio da Posse/SP, onde foi produzido cinco tipos de revestimentos por aspersão térmica pelo método de HVOF.

O revestimento 1310 VM corresponde a um carbeto de tungstênio e níquel, possuindo características como uma ótima resistência à corrosão e excelente resistência ao desgaste, assim como o Colmonoy $88 \mathrm{HV}$, que difere apenas por ter o níquel como base. O revestimento Woka 3102 é um compósito de alta dureza, ou cermet, possuindo em sua composição química um percentual de material cerâmico WC (carbeto de tungstênio) sobre uma matriz metálica de Co (cobalto) [5]. A liga Diamalloy 1005 (Inconel 625) possui uma porcentagem alta de níquel, apresentando ótima

\footnotetext{
* Contribuição técnica ao 69ำ Congresso Anual da ABM - Internacional e ao 14ํㅡㄹ ENEMET - Encontro Nacional de Estudantes de Engenharia Metalúrgica, de Materiais e de Minas, 21 a 25 de julho de 2014, São Paulo, SP, Brasil.
} 


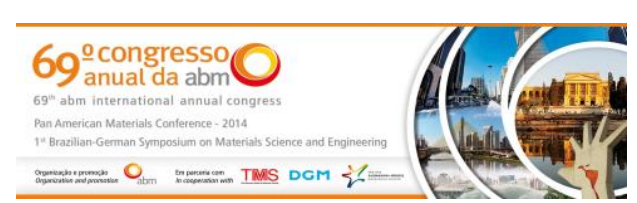

resistência ao desgaste, excelente resistência à corrosão e à alta temperatura. O CU - 104 - 2 possui quase 90 \% de Cu, apresentando uma dureza mais baixa, em contrapartida tem excelente resistência mecânica à alta temperatura. As composições químicas das camadas aspergidas estão apresentadas na tabela 1.

Tabela 1. Nomes comerciais e composição química dos revestimentos produzidos por aspersão térmica, estudados neste trabalho

\begin{tabular}{|c|c|c|c|c|c|}
\hline Composição Química & 1310VM & CU-104-2 & $88 \mathrm{HV}$ & Diamalloy 1005 & Woka3102 \\
\hline $\mathrm{Al}$ & & 9,62 & & 0,1 & \\
\hline $\mathrm{C}$ & 5,76 & & 0,8 & 0,01 & 5,45 \\
\hline Co & & & & 0,1 & 12,38 \\
\hline $\mathrm{Cr}$ & & & 15 & 21,4 & 0,2 \\
\hline $\mathrm{Cu}$ & & 89,4 & & 0,02 & \\
\hline $\mathrm{Fe}$ & & 0,95 & 3,5 & 0,1 & 0,2 \\
\hline $\mathrm{Mn}$ & & & & 0,22 & \\
\hline No & & & & 8,7 & \\
\hline $\mathrm{Nb}-\mathrm{Ta}$ & & & & 3,48 & \\
\hline $\mathrm{Ni}$ & 10,1 & & 57,2 & 65,6 & \\
\hline$P$ & & & & 0,015 & \\
\hline $\mathrm{S}$ & & & & 0,01 & \\
\hline $\mathrm{Si}$ & & & 4 & 0,3 & \\
\hline N2 & & & & 0,04 & \\
\hline $\mathrm{W}$ & 84,14 & & 16,5 & & 81,97 \\
\hline $\mathrm{B}$ & & & 3 & & \\
\hline
\end{tabular}

As análises metalográficas dos revestimentos, assim como medidas das partículas utilizadas no processo de aspersão térmica, foram realizadas no Microscópio Eletrônico de Varredura (MEV) da Central de Análises Químicas Instrumentais do Instituto de Química de São Carlos (CAQI/IQSC/USP) em um equipamento ZEISS LEO 440 (Cambridge, England). A análise de porosidade foi realizada de acordo com a norma ASTM E2109-07, pelo método B.

Ensaios de microdureza Vickers foram realizados em todos os revestimentos estudados e no material base, utilizando-se um microdurômetro Mitutoyo pertencente ao laboratóro da FATEC-Sorocaba, com carga de $100 \mathrm{Kgf}$.

Ensaios de adesão/coesão das camadas aspergidas foram realizados utilizando-se um dispositivo desenvolvido levando-se em conta a norma ASTM C 633-79 [6]. As dimensões dos corpos de prova determinados para a realização deste tipo de ensaio pode ser observado em Varavallo, 2012 [7]. Para a realização dos ensaios de aderência, colou-se um corpo de prova com aspersão em outro sem aspersão. A cola utilizada foi a Scoth Weld DP 460 Off White importada da 3M. Após a aplicação do adesivo, os corpos de prova foram levados a estufa para a cura da cola, a uma temperatura de $40^{\circ} \mathrm{C}$ durante 100 horas, conforme especificação do fabricante.

Os ensaios de tração foram realizados à temperatura ambiente em uma máquina de ensaios EMIC com capacidade de $300 \mathrm{KN}$ no laboratório da FATEC-Sorocaba, a uma velocidade de deformação de $2 \mathrm{~mm} / \mathrm{min}$. Foram determinados os valores do limite de resistência de aderência da camada aspergida, através da tensão aplicada ao corpo de prova quando ocorre a ruptura. Foram realizados três ensaios de adesão/coesão para cada tipo de camada aspergida estudada, e também no material base sem tratamento de superfície para a determinação da resistência adesiva da cola utilizada.

\footnotetext{
* Contribuição técnica ao $69^{\circ}$ Congresso Anual da ABM - Internacional e ao 14ํㅡㄹ ENEMET - Encontro Nacional de Estudantes de Engenharia Metalúrgica, de Materiais e de Minas, 21 a 25 de julho de 2014, São Paulo, SP, Brasil.
} 


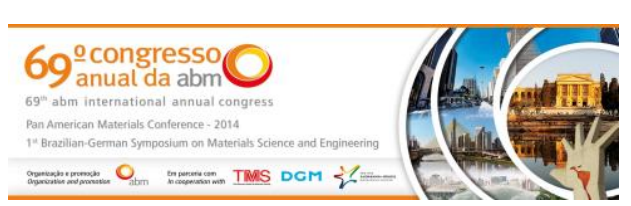

A caracterização dos revestimentos foi realizada conforme os tipos de fratura observados na figura 1.

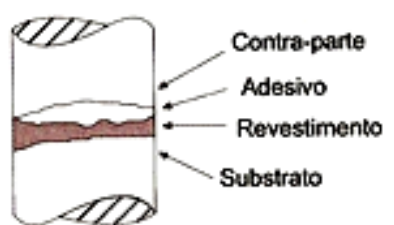

(a)

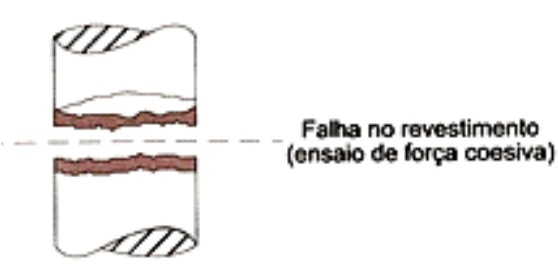

(c)

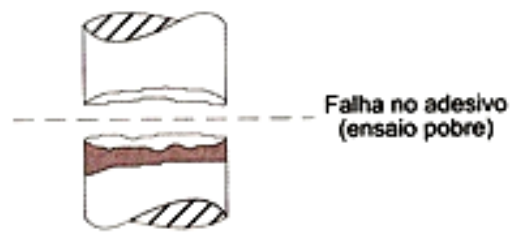

(b)

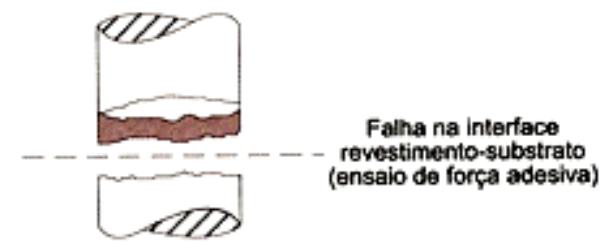

(d)

Figura 1. Tipos de fraturas resultantes do teste de adesão de revestimentos [8].

Devido à importância da qualidade superficial do material, os corpos de prova após o processo de aspersão foram submetidos a ensaios de rugosidade superficial, utilizando um rugosimetro portátil da Mitutoyo modelo SJ-201, com unidade de medida Ra (rugosidade média) e com um CUTT OFF de 0,8, pertencente ao Laboratório de Materiais da FATEC/Sorocaba. Foram realizadas seis medidas superficiais em diferentes partes para cada corpo de prova.

Para a determinação da resistência ao desgaste dos materiais aspergidos, utilizou-se um dispositivo de microdesgaste abrasivo por esfera fixa, conforme ilustrado na figura 2, alocado no Laboratório de Metalografia da FATEC-Sorocaba.

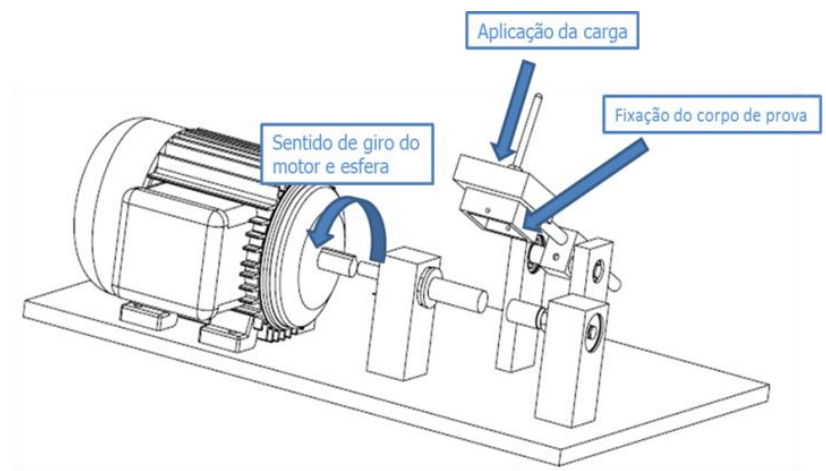

Figura 2. Esquema ilustrativo do dispositivo de desgaste microabrasivo.

Os ensaios de micro desgaste abrasivo por esfera fixa foram realizados em todos os materiais estudados, com uma rotação de 1493 RPM, aplicando uma carga 16,7 N. Os ensaios foram realizados nos tempos de 10 minutos sem a utilização de abrasivo. Para medir a calota impressa foi usado um estereoscópico da marca OLYMPUS modelo SZ61, com câmera de 6 megapixels e software Análise 2.0. Para uma calota de desgaste com geometria esférica produzida por uma esfera de raio "R" em uma amostra plana, o volume desgastado pode ser calculado de acordo com a equação (1) em que $R$ é o raio da esfera, b é o diâmetro médio da calota e $V$ é o volume de desgaste [9]. Através deste cálculo, determina-se que, quanto maior o volume desgastado, menor a resistência ao desgaste do material analisado. Pode-se também

* Contribuição técnica ao 69 Congresso Anual da ABM - Internacional e ao 14ํㅡㄹ ENEMET - Encontro Nacional de Estudantes de Engenharia Metalúrgica, de Materiais e de Minas, 21 a 25 de julho de 2014, São Paulo, SP, Brasil. 


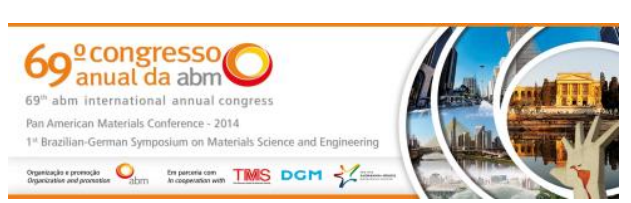

determinar o coeficiente de desgaste $(\mathrm{K})$, o qual pode ser interpretado como o volume de material desgastado em função da carga aplicada $(\mathrm{N})$ e da distância percorrida $(\mathrm{S})$, que pode ser calculada pela multiplicação do tempo de ensaio, rotação da esfera e perímetro da esfera (2. $\pi . R)$ de acordo com a equação (2) [9]. Este parâmetro mede a severidade do desgaste em que, quanto maior for $\mathrm{K}$, maior será a taxa de desgaste. É possível determinar também a altura da calota produzida $(h)$, levando em conta a equação (3), a fim de analisar se a calota produzida ultrapassou a camada produzida e atingiu o substrato.

$$
\begin{array}{ll}
\mathrm{V}=\pi \frac{\mathrm{b}^{4}}{64 \mathrm{R}^{2}}\left(\mathrm{R}-\frac{\mathrm{b}^{2}}{8 \mathrm{R}}\right) \approx \frac{\pi \mathrm{b}^{4}}{64 \mathrm{R}} & \text { para } \mathrm{b}<<<R \\
\mathrm{~K}=\frac{1}{\mathrm{~N} . \mathrm{S}} \cdot \frac{\pi \cdot \mathrm{b}^{4}}{64 . \mathrm{R}} & \text { para } \mathrm{b}<<<\mathrm{R} \\
h=\sqrt{\frac{V}{\pi R}} & \text { para } \mathrm{b}<<<\mathrm{R}
\end{array}
$$

\section{RESULTADOS E DISCUSSÃO}

\subsection{Análise de Porosidade e Microdureza Vickers}

Na tabela 2 é possível observar a porcentagem dos poros determinada para cada revestimento estudado. Observou-se que em 4 amostras a porcentagem excedeu $2 \%$. Ao analisar as partículas utilizadas para a produção dos revestimentos, observou-se que estas apresentavam tamanhos variados para o mesmo material, conforme apresentado na tabela 2 .

Tabela 2. Analise da porcentagem de porosidade

\begin{tabular}{cccc}
\hline Material & Média \% & Tamanho das partículas $[\mu \mathrm{m}]$ & Microdureza HV \\
\hline 1310 VM & 2,378 & $15-55$ & 1284 \\
\hline Colmonoy 88 HV & 2,078 & $15-55$ & 785 \\
\hline Cu- 104-2 & 3,452 & $7,6-65$ & 223 \\
\hline Diamalloy 1005 & 1,705 & $15-55$ & 401 \\
\hline Woka 3102 & 2,149 & $15-55$ & 841
\end{tabular}

O processo HVOF produz revestimentos com menor porosidade devido aos materiais serem utilizados na forma de pó, os quais se fundem durante o processo de HVOF e formam pequenas gotículas liquidas que aderem na camada e vão se contrapondo, caracterizando uma união mais consistente entre as partículas aspergidas.

Observa-se que a porosidade das camadas estudadas obtiveram valores muito próximos, devido ao processo de aspersão utilizado ter sido o mesmo para todos os materiais estudados. Porém, apesar de pequena, observa-se uma diferença entre os valores da porosidade encontrada. Devem-se levar em conta os parâmetros de

\footnotetext{
* Contribuição técnica ao 69ำ Congresso Anual da ABM - Internacional e ao 14ํㅡㄹ ENEMET - Encontro Nacional de Estudantes de Engenharia Metalúrgica, de Materiais e de Minas, 21 a 25 de julho de 2014, São Paulo, SP, Brasil.
} 


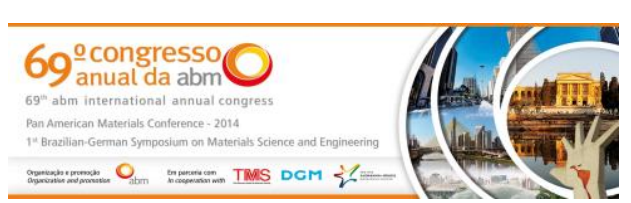

aplicação que influenciaram nos resultados encontrados neste trabalho, por isso houve uma pequena variação no percentual encontrado, em relação ao que descreve o boletim técnico do fabricante. É considerável que cada pó possui sua característica, mesmo sendo utilizado o mesmo método para todas as aplicações, os parâmetros de aplicação modificam-se de uma camada para outra. Talvez a maior porosidade encontrada para o Cu 104-02 esteja relacionado com a maior variação dos tamanhos da partícula utilizada para a formação deste revestimento.

Através dos ensaios de microdureza, observou-se que o substrato AISI 1020 apresentou uma microdureza de aproximadamente $200 \mathrm{HV}$. Os revestimentos 1310 VM, Woka 3102 e Colmonoy 88 HV, apresentam uma dureza elevada, já o revestimento Diamalloy 1005 apresentou dureza média, e o Cu-104-02 teve uma dureza média próxima ao do substrato. Os valores da microdureza dos revestimentos podem ser observados na tabela 2.

Maranho [1] determinou, em um estudo da influência dos parâmetros do processo de aspersão térmica por HVOF na aplicação de revestimentos em ferro fundido branco multicomponentes, que a elevação da porcentagem da porosidade levou a diminuição da dureza dos revestimentos. Resultados semelhantes foram obtidos por Varavallo et al. [7], que determinaram que revestimentos produzidos por materiais em nano-pó apresentaram menores porcentagens de porosidade e maiores durezas com relação a revestimentos produzidos por materiais em forma de vareta. Segundo Lima [8], os valores de microdureza variam consideravelmente em um mesmo revestimento.

Porém, neste trabalho observa-se que a microdureza dos revestimentos está diretamente relacionada com a composição química destes. Materiais que apresentam tungstênio em sua composição apresentaram as maiores durezas. $\mathrm{O}$ 1310 VM, que apresenta $84,14 \%$ de tungstênio e 10,1\% de níquel, apresentou a maior dureza dentre todos os revestimentos analisados, seguido do Woka $3102 \mathrm{com} 81,97 \%$ de tungstênio e 12,38\% de cobalto, e Colmonoy $88 \mathrm{HV}$ com 16,5\% de tungstênio e $57,2 \%$ de niquel. O Diamalloy 1005 , com alta quantidade de níquel (65,6\% de níquel e $21,4 \%$ de cromo) apresentou uma dureza menor que o Colmonoy $88 \mathrm{HV}$. Já o material de menor dureza foi o Cu-104-2, material a base de cobre $(89,4 \%)$ e alumínio $(9,62 \%)$.

\subsection{Análises Micrograficas}

A figura 3 ilustra as micrografias e a determinação da espessura das camadas produzidas por aspersão térmica estudadas neste trabalho. Houve uma variação na espessura do revestimento depositado no substrato, as quais se apresentaram entre $110 \mu \mathrm{m}$ e $368 \mu \mathrm{m}$.

O revestimento Woka 3102 apresenta uma espessura média de $256 \mu \mathrm{m}$. Na amostra 1310 VM, o revestimento apresenta uma espessura média de 122,5 $\mu \mathrm{m}$. O revestimento de Cu-104-02 possui uma espessura média de 158,8 $\mu \mathrm{m}$. A espessura média do revestimento Diamalloy 1005 é $256 \mu \mathrm{m}$. Já o revestimento Colmonoy 88 HV possui uma espessura média bem maior do que as outras, com 362,5 $\mu \mathrm{m}$.

\footnotetext{
* Contribuição técnica ao 69ำ Congresso Anual da ABM - Internacional e ao 14ํㅡㄹ ENEMET - Encontro Nacional de Estudantes de Engenharia Metalúrgica, de Materiais e de Minas, 21 a 25 de julho de 2014, São Paulo, SP, Brasil.
} 


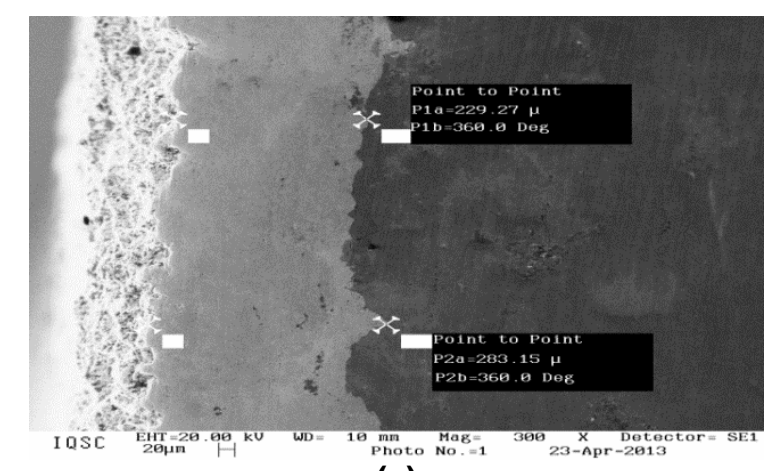

(a)

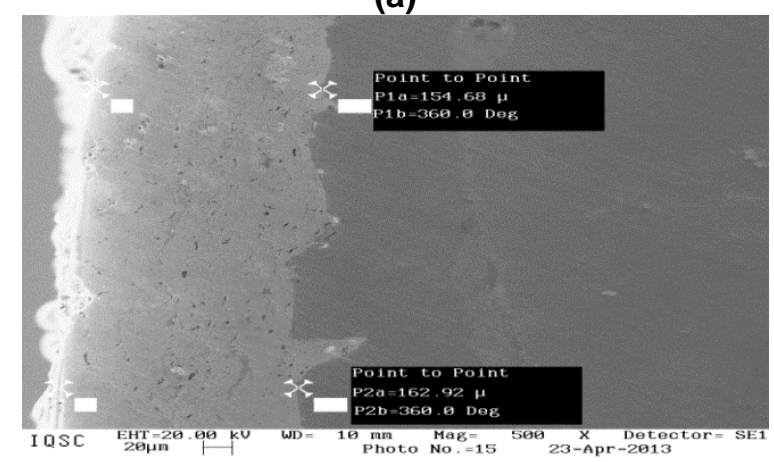

(c)

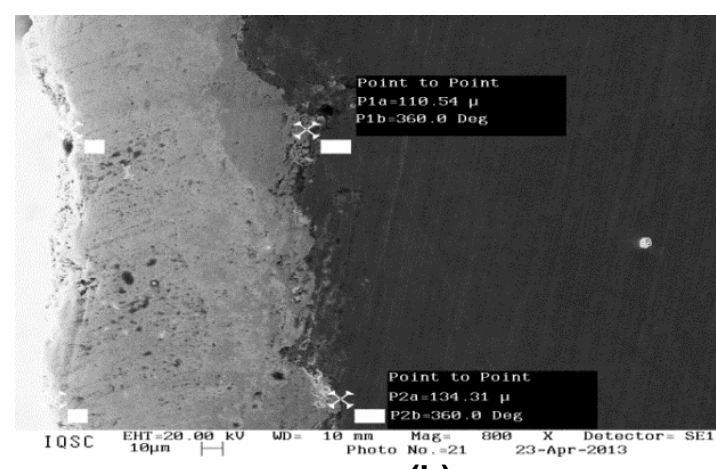

(b)

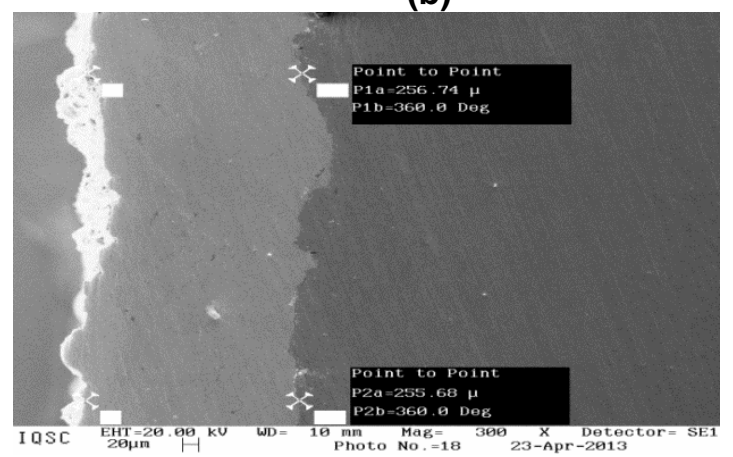

(d)

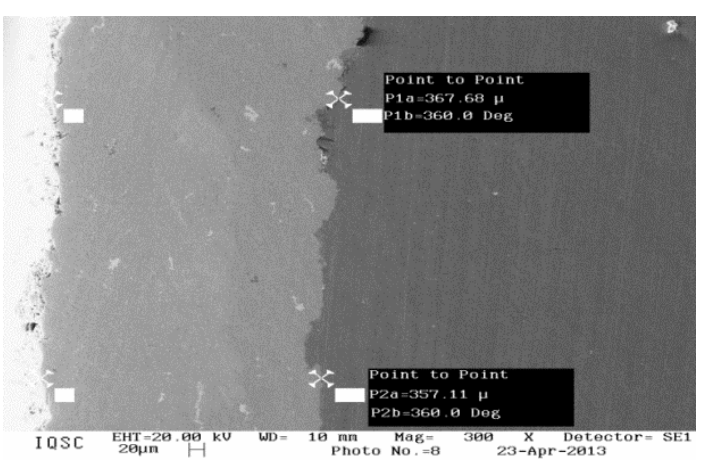

(e)

Figura 3. Metalografia das camadas aspergidas (a) Woka 3102, (b) 1310 VM, (c) Cu-104-2, (d) Diamalloy 1005 e (e) Colmonoy 88 HV

\subsection{Ensaios de Adesão / Coesão}

Os resultados do ensaio de adesão estão apresentados na tabela 3, determinando os valores de resistência à tração e tipo de falha encontrada em cada camada estudada.

Tabela 3. Resultados obtidos através do ensaio de adesão

\begin{tabular}{ccc}
\hline Material & Adesão [kgf] & Tipo de Falha \\
\hline 1310 VM & 2191,67 & na cola \\
\hline Cu-104-2 & 1394 & coesiva e na cola \\
\hline Colmonoy 88 HV & 1689 & coesiva e na cola \\
\hline Diamalloy 1005 & 2034 & coesiva e na cola \\
\hline Woka 3102 & 2590,5 & na cola \\
\hline cola & 2039,67 & - \\
\hline
\end{tabular}

Observa-se que os materiais 1310 VM e Woka 3102, que apresentaram as maiores durezas, foram aqueles que obtiveram os maiores limites de adesão, conforme ilustra

\footnotetext{
* Contribuição técnica ao 69ำ Congresso Anual da ABM - Internacional e ao 14ํㅡㄹ ENEMET - Encontro Nacional de Estudantes de Engenharia Metalúrgica, de Materiais e de Minas, 21 a 25 de julho de 2014, São Paulo, SP, Brasil.
} 


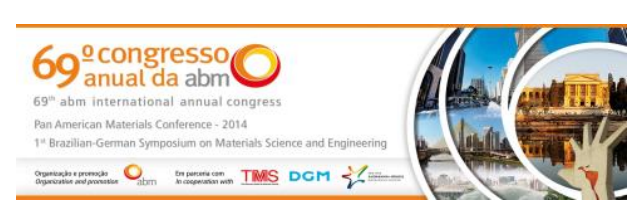

a figura 4. Os valores de adesão obtidos para estes materiais superaram os valores da cola, utilizada como referência.

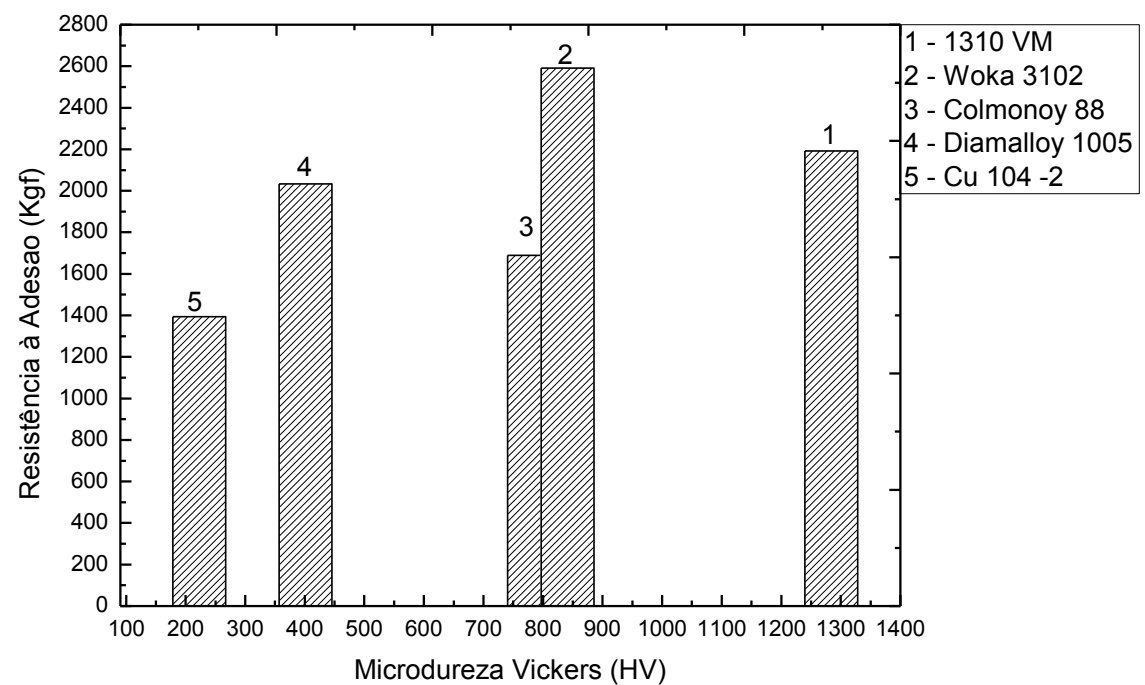

Figura 4. Resistência à adesão em função da microdureza das camadas aspergidas.

O material $\mathrm{Cu} 104-2$, que apresentou o menor valor de dureza, apresentou também os menores valores de adesão. Já o Colmonoy $88 \mathrm{HV}$, apesar da sua dureza intermediária dentre os materiais estudados, apresentou limite de adesão próximo ao $\mathrm{Cu}$ 104-2.

Assim, a dureza da camada aspergida é um parâmetro que influencia de forma direta no limite de adesão das camadas aspergidas, mas também outros parâmetros devem ser considerados, como por exemplo, a espessura das camadas aspergidas. Observase que o Colmonoy $88 \mathrm{HV}$, que apresentou menor valor de adesão, possui espessura média de camada aspergida de $362,5 \mu \mathrm{m}$, o maior valor dentre todos os materiais estudados, conforme ilustra a tabela 5. Isto demonstra que a dureza é um valor importante para a adesão da camada aspergida no substrato, porém camadas muito espessas podem prejudicar o desempenho das camadas produzidas por aspersão térmica.

Observa-se também, com relação ao tipo de falha, que os materiais com maior resistência adesiva (1310 VM e Woka 3102) apresentaram falha na cola. Assim, devese considerar que os valores de adesão apresentados não representam a real resistência à adesão destas camadas, mas determinam que estas são superiores ao valor da cola estudada. Já os materiais Colmonoy 88HV, Diamalloy 1005 e 104-2, apresentaram falha mista, na cola e coesiva, falha esta que determina a real resistência adesiva dos materiais estudados, mostrando que parte das camadas apresentaram falha na camada. Porém, nenhuma camada estudada apresentou falha adesiva, mostrando que a ancoragem da camada ao substrato foi eficiente.

Observa-se, através da análise da figura 5, que a resistência à adesão das camadas estudadas não tiveram influência direta da porcentagem de porosidade determinada para cada material.

\footnotetext{
* Contribuição técnica ao 69ำ Congresso Anual da ABM - Internacional e ao 14ํㅡㄹ ENEMET - Encontro Nacional de Estudantes de Engenharia Metalúrgica, de Materiais e de Minas, 21 a 25 de julho de 2014, São Paulo, SP, Brasil.
} 

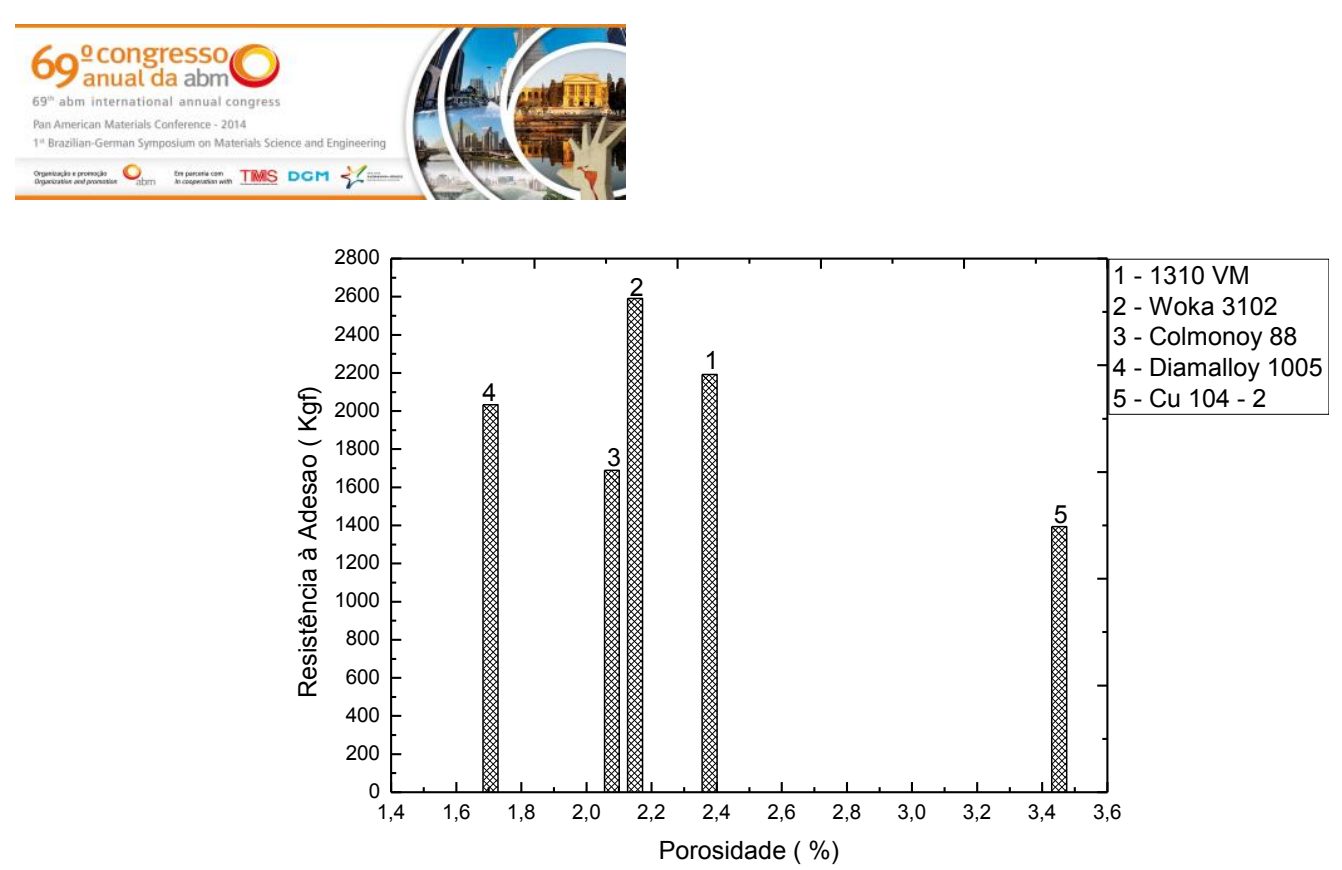

Figura 5. Gráfico da porosidade versus resistência à adesão.

\subsection{Ensaio de Rugosidade}

A figura 6 ilustra os valores da rugosidade em $\mathrm{Ra}(\mu \mathrm{m})$ e sua comparação com a porosidade das camadas produzidas. Verifica-se que a rugosidade não está relacionada com a porosidade, para as camadas estudadas neste trabalho. Observam-se as maiores rugosidades para os materiais com menor (Diamalloy 1005) e maior (Cu-104-2) porosidade.

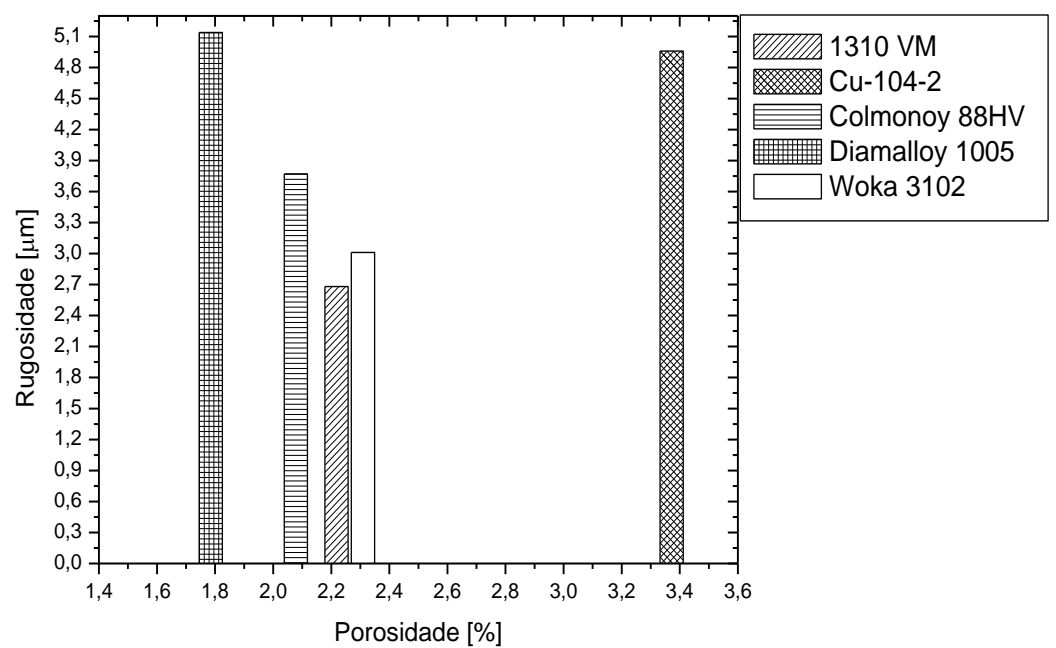

Figura 6. Relação da porosidade com a rugosidade dos revestimentos estudados neste trabalho

Observa-se que os valores de rugosidade não possui relação com a porosidade, estando diretamente ligada á preparação da superfície. As lamelas que formam o revestimento seguem a forma da superfície, se sobrepondo uma camada à outra até completarem o processo de deposição. Assim, as irregularidades da superfície do substrato se mantém até a superfície da camada.

\subsection{Ensaios de Microdesgaste Abrasivo}

A figura 7 ilustra o volume de desgaste e diâmetro da calota produzida nos ensaios de microdesgaste para cada material estudado.

\footnotetext{
* Contribuição técnica ao 69ำ Congresso Anual da ABM - Internacional e ao 14ํㅡㄹ ENEMET - Encontro Nacional de Estudantes de Engenharia Metalúrgica, de Materiais e de Minas, 21 a 25 de julho de 2014, São Paulo, SP, Brasil.
} 


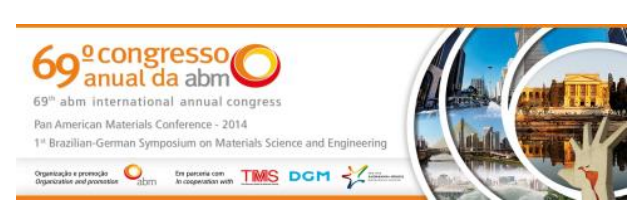

Tabela 5. Altura das camadas produzidas por aspersão térmica

\begin{tabular}{|ccc|}
\hline Material & Altura da calota $[\mu \mathrm{m}]$ & Espessura do revestimento $[\mu \mathrm{m}]$ \\
\hline 1310 VM & $\mathrm{X}$ & 122,5 \\
\hline Cu-104-2 & 208,54 & 158,8 \\
\hline Colmonoy 88 HV & 58,4 & 362,5 \\
\hline Diamalloy 1005 & 83,4 & 256 \\
\hline Woka 3102 & $\mathrm{X}$ & 256 \\
\hline
\end{tabular}

\section{CONCLUSÃO}

Um AISI 1020 é um aço de baixo carbono com apenas 0,2\% C, tem características como fácil usinagem, alta tenacidade e baixa dureza, isso faz com que sejam necessários a deposição de novos revestimentos para se ter maior resistência ao desgaste e a corrosão. Materiais que recebem esses revestimentos elevam suas propriedades mecânicas, possuem baixos níveis de óxidos e baixa porosidade, como por exemplo, a aspersão térmica pelo processo Hipersônico (HVOF) que é um processo moderno no mercado, utiliza materiais de revestimentos com uma combinação de cerâmicas e metais, e ligas de materiais com elevado resistência.

De acordo com os resultados obtidos nesta pesquisa os materiais de revestimentos 1310 VM, Woka 3102 e colmonoy 88 HV, possuem dureza elevada devido a sua composição química que inclui ligas de carbeto de tungstênio a base de níquel.

Foi possível verificar que a porosidade não está relacionada à dureza, espessura e rugosidade dos revestimentos, e sim com os parâmetros de aplicação dos revestimentos. Analisou-se que os revestimentos apresentaram uma porosidade em média de $2 \%$, que se dá devido ao processo de aspersão térmica utilizado para aplicação das camadas - HVOF.

A resistência à adesão foi maior para os revestimentos de maior dureza, porém percebeu-se que a espessura da camada produzida pode influenciar na resistência adesiva destes. A resistência ao desgaste está diretamente relacionada á dureza do revestimento estudado. Quanto maior a dureza, maior a resistência ao desgaste e menor a taxa de desgaste.

\section{Agradecimentos}

Agradecimentos à empresa Ogramac Indústria e Comércio Ltda, pela produção das camadas, à FATEC - Sorocaba pela disponibilização de seus laboratórios e oficina, e à CAQI/IQSC/USP.

\section{REFERÊNCIAS}

1 Maranho O. Aspersão térmica de ferro fundido branco multicomponente [Doutor em Engenharia Mecânica]. São Paulo: Escola Politécnica da Universidade de São Paulo; 2006.

2 Lima CRC, Trevisan RE. Aspersão térmica: fundamentos e aplicações. $2^{a}$ ed. São Paulo: Artiliber, 2007.

3 American Society for Testing and Materials. ASTM E 2109: Test method for determining area percentage porosity in thermal sprayed coating. West Conshohocken. ASTM International Handbook. 2007.

4 Macedo DT, Gouvea CAR Cruvinel LB, Nucci R. Casteletti LC. Avaliação de revestimentos produzidos por aspersão térmica em substrato da liga de alumínio 7075-

\footnotetext{
* Contribuição técnica ao 69ำ Congresso Anual da ABM - Internacional e ao 14ํㅡㄹ ENEMET - Encontro Nacional de Estudantes de Engenharia Metalúrgica, de Materiais e de Minas, 21 a 25 de julho de 2014, São Paulo, SP, Brasil.
} 
T3, In: Congresso Brasileiro de Engenharia e Ciência dos Materiais. 17ㄹ, 2006, Foz do Iguaçu: CBECIMat, 2006.

5 Geremia L. Analise do desgaste erosivo em revestimentos aspergidos termicamente. UFRGS, São Leopoldo, 2006. [Acesso em 15 de Abril de 2013]. Disponível em: $<$ http://www.rijeza.com.br/sites/default/files/desgaste-erosivo-revestimentos.pdf $\geq$.

6 American Welding Society. AWS: Thermal spraying: practice, theory and applications, Miami, 1985.

7 Varavallo R, Manfrinato MD, Rossino LS, Maluf O, Camargo F. Adhesion of Thermally Sprayed Metallic Coating. Journal of ASTM International. 2012; 9(2): 1-11.

8 Lima CRC, Trevisan RE. Aspersão térmica: fundamentos e aplicações. São Paulo: Artiliber, 2002.

9 Rutherford KL, Hutchings IM. A micro-abrasive wear test with particular application to coated systems. Surface and Coatings Technology. 1996; 7 9: 231-239.

10 Guerrero GE, Paredes RS, Vlassov D, Pukasiewicz A. Influência da geometria do bocal da pistola de aspersão térmica por arco elétrico na microestrutura de revestimentos do aço AWS 309L, In: Congresso Brasileiro de Engenharia e Ciência dos Materiais, 17․ 2006, Foz do Iguaçu: CBECIMat, 2006.

11 Lima CRC Trevisan RE. Ensaios de adesão em revestimentos obtidos por aspersão térmica a plasma. Unimep, Piracicaba. 1999. [Acesso em: 12 de Março de 2013]. Disponível em: <http://www.unimep.br/phpg/editora/revistaspdf/rct13art04.pdf>.

12 Manfrinato Md, Varavallo R, Rossino L S, Camargo F, Maluf O. Metallic Coating Adhesion Obtained Through Spraying Testing. In: Internation Federation for Heat Treatment and Surface Engineering. 2010; 18.

13 Maul MA. Analise por técnica eletroquímica da porosidade de revestimentos sobre superfícies metálicas [Mestre em Engenharia de Materiais]. Curitiba: Universidade Federal do Paraná; 2001.

14 Menezes DD. Avaliação da resistência à corrosão de revestimentos de alumínio aplicados pelas técnicas de arco elétrico e chama convencional, em meio cloreto [Doutora em Ciências de Engenharia Metalurgica e de Materiais]. Rio de Janeiro:. Universidade Federal do Rio de Janeiro; 2007.

* Contribuição técnica ao 69ำ Congresso Anual da ABM - Internacional e ao 14ํㅡㄹ ENEMET - Encontro Nacional de Estudantes de Engenharia Metalúrgica, de Materiais e de Minas, 21 a 25 de julho de 2014, São Paulo, SP, Brasil. 